University of Nebraska - Lincoln

DigitalCommons@University of Nebraska - Lincoln

2-2002

\title{
Visual Predators Select for Crypticity and Polymorphism in Virtual Prey
}

Alan B. Bond

University of Nebraska - Lincoln, abond1@unl.edu

Alan Kamil

University of Nebraska - Lincoln, akamil1@unl.edu

Follow this and additional works at: https://digitalcommons.unl.edu/bioscibehavior

Part of the Behavior and Ethology Commons

Bond, Alan B. and Kamil, Alan, "Visual Predators Select for Crypticity and Polymorphism in Virtual Prey" (2002). Papers in Behavior and Biological Sciences. 38.

https://digitalcommons.unl.edu/bioscibehavior/38

This Article is brought to you for free and open access by the Papers in the Biological Sciences at DigitalCommons@University of Nebraska - Lincoln. It has been accepted for inclusion in Papers in Behavior and Biological Sciences by an authorized administrator of DigitalCommons@University of Nebraska - Lincoln. 


\title{
Visual Predators Select for Crypticity and Polymorphism in Virtual Prey
}

\author{
Alan B. Bond ${ }^{a}$ and Alan C. Kamil a,b \\ a Nebraska Behavioral Biology Group, School of Biological Sciences, University of Nebraska-Lincoln, Lincoln, Nebraska 68588-0I I8, USA \\ b Department of Psychology, University of Nebraska-Lincoln, Lincoln, Nebraska 68588-0I I8, USA \\ Corresponding authors _ A. B. Bond, abond@unl.edu ;A. C. Kamil, akamil@unl.edu
}

\begin{abstract}
Cryptically colored animals commonly occur in several distinct pattern variants. Such phenotypic diversity may be promoted by frequency-dependent predation, in which more abundant variants are attacked disproportionately often, but the hypothesis has never been explicitly tested. Here we report the first controlled experiment on the effects of visual predators on prey crypticity and phenotypic variance, in which blue jays (Cyanocitta cristata) searched for digital moths on computer monitors. Moth phenotypes evolved via a genetic algorithm in which individuals detected by the jays were much less likely to reproduce. Jays often failed to detect atypical cryptic moths, confirming frequency-dependent selection and suggesting the use of searching images, which enhance the detection of common prey. Over successive generations, the moths evolved to become significantly harder to detect, and they showed significantly greater phenotypic variance than non-selected or frequency-independent selected controls.
\end{abstract}

Polymorphic cryptic coloration has been recorded in a variety of prey species, including grasshoppers, ${ }^{1}$ homoptera, ${ }^{2}$ mantids, ${ }^{3}$ and bivalves, ${ }^{4}$ but it is particularly evident in the noctuid moths that rest concealed on tree trunks and other vegetation during the day. ${ }^{5,6}$ Roughly $45 \%$ of North American moths of the genus Catocala are polymorphic, with some species occurring in as many as nine different forms. ${ }^{7}$ In other noctuid genera, the adults are "massively polymorphic", varying continuously in appearance over an exceedingly broad range. .-10 $^{-10}$

Frequency-dependent selection, in which more common prey types are attacked disproportionately often, has been assumed to play a role in maintaining color pattern polymorphism. ${ }^{11,12}$ If predators respond to changes in relative abundance by switching away from once common prey when they become rare, such "apostatic selection" could prevent rare prey types from being eliminated and thereby maintain balanced numbers of the different morphs. Although many ecological mechanisms can produce frequency-dependent selection, polymorphism in cryptic prey species probably reflects the fact, first noted by Poulton ${ }^{13}$ in 1890, that it is difficult and time-consuming to hunt for several different items simultaneously. Consequently, visual predators tend to search at any moment for only a limited number of prey types, focusing on the distinctive features of common ones and effectively overlooking the others, a phenomenon known as "hunting by searching image." 14 Recent studies have confirmed the occurrence of searching image effects, demonstrating that the ability to detect cryptic prey increases when items of similar appearance are encountered in rapid succession and that a search for one cryptic prey type can actively interfere with the detection of alternative forms. ${ }^{15-18}$

Because the dynamic interplay between predator behavior and prey appearance is difficult to evoke under controlled conditions, much of the earlier empirical support for frequencydependent selection of cryptic prey was fragmentary and indirect. ${ }^{19}$ To circumvent this constraint, we developed a "virtual ecology", in which captive blue jays hunt for artificial, digital moths on computer displays. The preparation allows realistic, repeatable experimental investigations of the ecological processes involved in prey evolution. Our previous work with this system has shown that predators searching for a set of fixed prey types do exhibit frequency-dependent selection, that such selection does serve to maintain stable prey polymorphism, and that the effect is almost certainly attributable to hunting by searching image. ${ }^{18,19}$

Because frequency-dependent selection operates against common, familiar phenotypes, it should also lead to the proliferation of new, disparate phenotypes in an initially monomorphic prey population. ${ }^{4,20-22}$ This prediction has been subjected to only limited experimental testing. In our previous study of virtual ecology, frequency-dependent selection produced stable dynamics among a set of three morphs, but the consequences of adding new morphs seemed to depend on how difficult they were to detect. ${ }^{18}$ In one case, the new morph was similar in crypticity to those in the initial population, and a stable configuration of four prey types was produced. A second new morph, however, was so cryptic and distinctive that few of them were ever discovered. This new morph came to dominate the population completely and drove all of the others to extinction. The dynamics that one might expect from natural genetic changes in prey populations are therefore unclear. By extending our virtual ecology paradigm through the addition of a genetic algorithm, we have found a means of addressing this issue and testing whether frequency-dependent selection not only maintains but actively encourages the evolution of phenotypic diversity.

\section{Virtual ecology}

Our methods derive from a naturally occurring predatorprey system. In eastern North America, blue jays commonly prey on cryptically colored noctuid moths during the daytime, discovering the insects even while they are resting motionless on tree trunks. ${ }^{5}$ Jays exhibit similarly impressive detection abilities when required to locate moths in projected images in the laboratory, providing a convincing emulation of natural foraging behavior. ${ }^{23-25}$ To furnish our jays with a functional virtual ecology, we generated synthetic, digital moths - bilaterally symmetrical triangles about $6 \mathrm{~mm}$ high - and displayed them to the birds overlaid on a complex, granular background (Figure 1). ${ }^{18}$, 19 To avoid potential problems with avian color perception, the displays were constructed using a 64-level grey scale. ${ }^{26}$

Each moth phenotype was constructed from specifications in a virtual chromosome, through an algorithm derived from salient features of the genetics of lepidopteran wing patterns. ${ }^{27-30}$ These included genes that coded for individual patches of pattern elements, genes that produced global changes in brightness or contrast, and linkage mechanisms that protected favorable genotypes from being broken up by recombination. As in real moths, phenotypic traits were polygenic, in that the intensity of any given pixel was the result of additive interactions among a large number of loci.

Our experimental design was similar to that of more traditional selection studies, contrasting the selective effects of jay 
predation in several experimental lineages with the results of control treatments in which selection was eliminated or constrained. In each of our experimental and control lineages, the moth population was maintained at a constant level of 200 individuals over 100 successive, non-overlapping generations. Reproduction entailed choosing two individual chromosomes according to the selection algorithm and recombining them into a

\section{a Parental population $\left(\mathrm{P}_{0}\right)$}
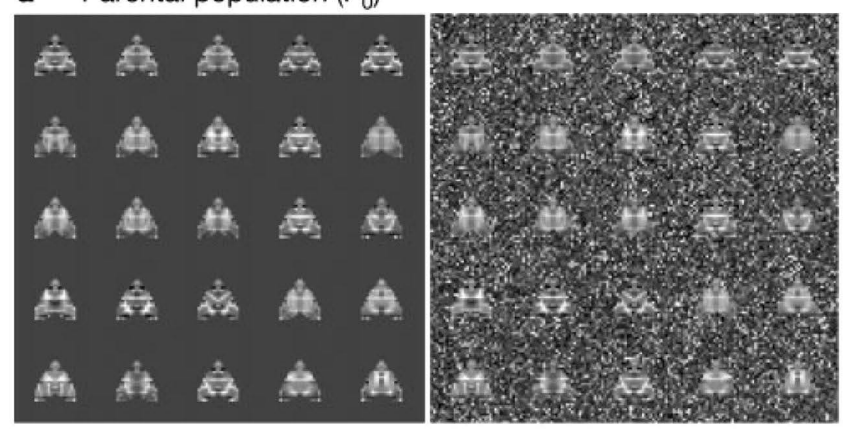

b Experimental results $\left(\mathrm{F}_{100}\right)$

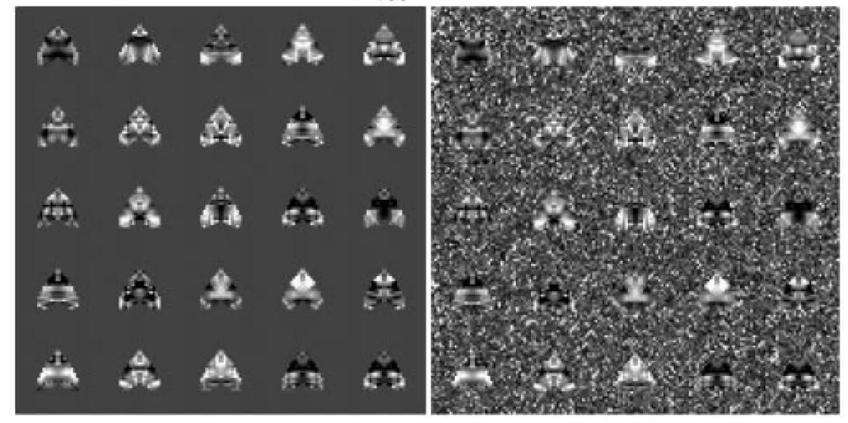

c Non-selected controls $\left(F_{100}\right)$

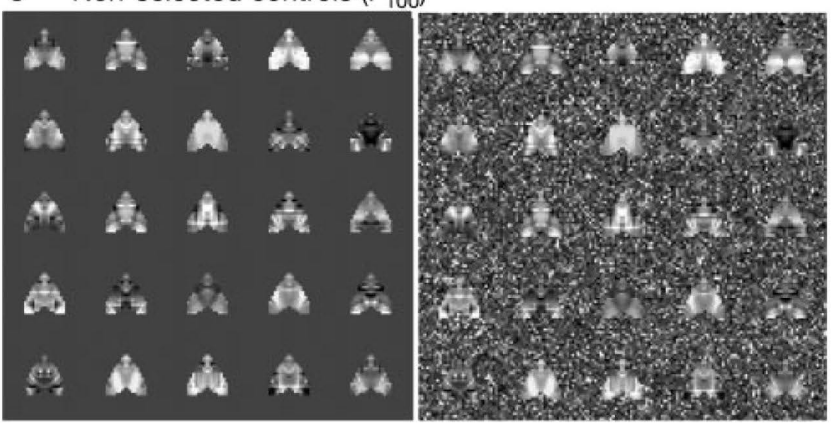

d Frequency-independent controls $\left(F_{100}\right)$

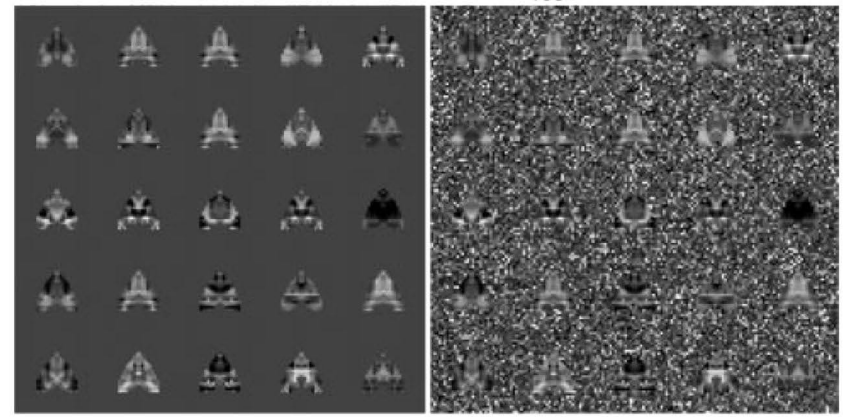

Figure I. Samples of digital moths, shown on uniform grey (left) and cryptically textured (right) backgrounds, from the parental population, $\mathrm{P}_{0}(\mathrm{a})$, and from the $F_{100}$ generations from the non-selected lines (b), the frequencyindependent selection lines (c), and the experimental lines selected by the jays (d). We note that moths from the experimental lines are generally more cryptic then those in the non-selected lines and more variable in appearance than those in the lines subjected to frequency-independent selection. single offspring genome. The offspring were then subjected to a mutation process that randomly inverted individual bits. To produce a new generation, these selection, recombination and mutation steps were repeated until a full array of 200 progeny had been obtained. The previous population was then discarded and replaced with the new individuals.

An initial, monomorphic parental population with moderate phenotypic variability (Figure 1a) was generated from a template provided by a moth image from an earlier experiment. ${ }^{19}$ This population was then hunted by four jays, each of which was required to search for the moths presented one at a time on a computer display. ${ }^{18,} 19$ Each moth in the population was presented to one of the jays once in the course of a daily session. Half of these daily trials, on a random basis, contained a moth embedded somewhere in the display, while the other half showed only the background. If a jay correctly detected a moth and pecked at it, the bird was rewarded with a food pellet; if it did not find a moth, the bird pecked a central green circle to initiate the next trial.

At the end of each day, the accuracy and latency of the birds responses were scored and entered into the selection algorithm, which favored those moths that were most difficult for the jays to detect. The moth population was allowed to reproduce, and the resulting generation was presented to the jays on the succeeding day. Beginning each time with the same parental population, we produced three successive experimental lineages, continuing selection in each case out to the $\mathrm{F}_{100}$ generation. Between runs, the jays were given 30 days of exposure to the parental population under stationary, non-evolving conditions to return them to a consistent baseline.

To test whether observed changes in crypticity and phenotypic variance in the experimental lines were statistically meaningful, the results were contrasted with those from two sets of control lineages, one employing no selective agency and the other using frequency-independent directional selection based on parameters derived from global aspects of the jays' behavior. In both of the control treatments, we used the same population size, the same initial parental population, the same backgrounds and the same mutation rate as in the experimental trials. In the non-selected lineages, however, the moths were never presented to jays, and the probability of being chosen to breed was uniform across the moth population, irrespective of phenotype. This provided a control for the occurrence of directional selection for crypticity in the experimental treatments.

The second control was designed to assess our primary hypothesis, that frequency-dependent selection promotes increased phenotypic diversity. This required comparison to lineages in which selection was independent of the frequency of particular phenotypes, but was otherwise similar in intensity and direction to that produced in the experimental lines. For these control lineages, therefore, we determined the functional relationship between detection and crypticity for the jays, averaging over all of the results in the experimental lines. This function was then used to determine the probability of a moth's being chosen to breed. In the experimental trials, the jays appeared to allocate their searching effort at least in part on the basis of the average degree of difficulty they experienced in finding the moths: Cryptic moths were detected more accurately and rapidly when the rest of the individuals in the population were cryptic than when the rest of them were relatively conspicuous $\left(r^{2}=0.9\right.$, student's $t(1)=6.74, P<0.002)$.

This "search rate" 31 or "caution" 15 effect has been observed in other experimental studies of foraging behavior, and although caution cannot produce frequency-dependent predation when prey are presented in a randomized sequence, ${ }^{32}$ it provided a solid basis for an alternative, frequency-independent control. The selection algorithm in the frequency-independent lineages was based on the empirical relationships between crypticity and detection performance in the experimental trials and fitted to the observed effects of mean population crypticity. We 
generated 200 selection lines of 100 successive generations using the non-selected and frequency-independent control treatments to provide controls for the selective effects of jay predation.

\section{Frequency-dependent selection}

In our previous studies of virtual ecology, which used morphs of fixed appearance, we found clear evidence of frequency-dependent selection and were able to show that such selection served to maintain a stable prey polymorphism. To confirm that a similar process was also operating on the continuously variable morphs in our current experiment, we examined the factors influencing detection accuracy in the experimental lines. Subjects varied in their ability to detect cryptic prey, with two of the birds consistently showing higher accuracy than the others $\left(F_{3,400} \geq 49.67, P<0.0001\right)$. Mean accuracy across subjects remained almost constant over the course of each experimental lineage $\left(r^{2}=0.04 ; t(1)=1.18\right.$, NS) but increased significantly across successive lineages $\left(F_{2,30}=10.48, P<0.001\right)$. The pattern of variation of accuracy over time was quite complex, exhibiting a strong, regular oscillation with a fundamental period of about 10 generations (minimum Durbin-Watson statistic, $\mathrm{DW}(10)=$ $1.503, P<0.001)$. Oscillations in accuracy of roughly the same periodicity were also observed in our previous work on selection with fixed morphs, ${ }^{19}$ where they were linked to the rise and fall in abundance of the corresponding prey types. Although we cannot readily categorize phenotype abundance here, the accuracy oscillation presumably derives from a similar unstable feedback between the predators' focal search for a limited number of visual features and the resulting selective pressure against prey that carry those features.

More cogent evidence of the selective mechanisms can be obtained from close examination of the effects of trial sequence. If the jays were using searching images in their pursuit of digital moths, cases in which several moths of similar appearance were presented in succession would be expected to produce a temporary enhancement in detection, while moths of disparate appearance should be more likely to be overlooked. ${ }^{18}$ Stepping through the results, trial by trial, we extracted the phenotypic distance between each moth and the most recent previously detected moth. We corrected this dissimilarity measure for the mean dissimilarity and crypticity among all moths in each population, producing a relative measure of successional dissimilarity for all individuals in all three experimental lines.

For analysis, we pooled the data from the three lines and divided them into three groupings on the basis of moth crypticity. Within each grouping, trials were sorted by relative dissimilarity and blocked into sets of 100 . Detection accuracy in each set was then analyzed as a function of dissimilarity and crypticity grouping (Figure 2). There was a strong, significant effect of crypticity level on accuracy $\left(F_{2554}=709, P<0.0001\right)$ : the mean accuracy on trials with low-crypticity moths was 0.92 , with medium-crypticity moths 0.89 , and with high-crypticity moths 0.76 . The relationship between accuracy and dissimilarity was noticeably affected by crypticity. At low- and medium-crypticity levels, the slopes of the regression of accuracy on dissimilarity were not significant $\left(r^{2}\right.$ $\leq 0.021 ; t(1) \leq 1.97, N S)$. The high crypticity grouping, on the other hand, showed a strong negative relationship between accuracy and dissimilarity $\left(r^{2}=0.35 ; t(1)=-10.3, P<0.0001\right)$.

That atypical cryptic prey items should be more difficult to detect is precisely what one would expect from the operation of searching images, and it substantiates our assumption that moths in the experimental lineages were subjected to frequencydependent selection. Sequential dissimilarity had no evident effect on the detection of relatively conspicuous prey, however, replicating numerous previous findings that searching image mainly plays a role in the detection of cryptic stimuli, $15,1617,33$. In addition, to our knowledge these results provide the first evidence of searching image effects where prey appearance was continuously variable; all previous studies have employed a limited number of fixed, easily distinguishable prey types.

\section{Selection effects on crypticity}

Our next concern was whether jay predation resulted in directional selection for crypticity over the course of the study, that is, whether the moths evolved to become more difficult to detect. Mean crypticity indices from the three experimental lines rose from 0.47 in the parental generation to an average of 0.60 in the last five generations, an increase of $29 \%$ (Figure 3). Crypticity also increased in the non-selected control lines, apparently as a result of initial conditions: the parental population was slightly less cryptic than the long-term average of non-selected lines, causing a gradual drift towards greater crypticity in the first 100 generations. All three experimental lines, however, did display a significantly higher level of crypticity in the $\mathrm{F}_{100}$ generation than did the non-selective controls (Figure $3 a, F_{1,40596} \geq$ 11.51, $P<0.0001)$.

Jay predation thus resulted in unequivocal, directional selection for increased crypticity in the digital moth populations, as can readily be confirmed in even small, arbitrary samples of
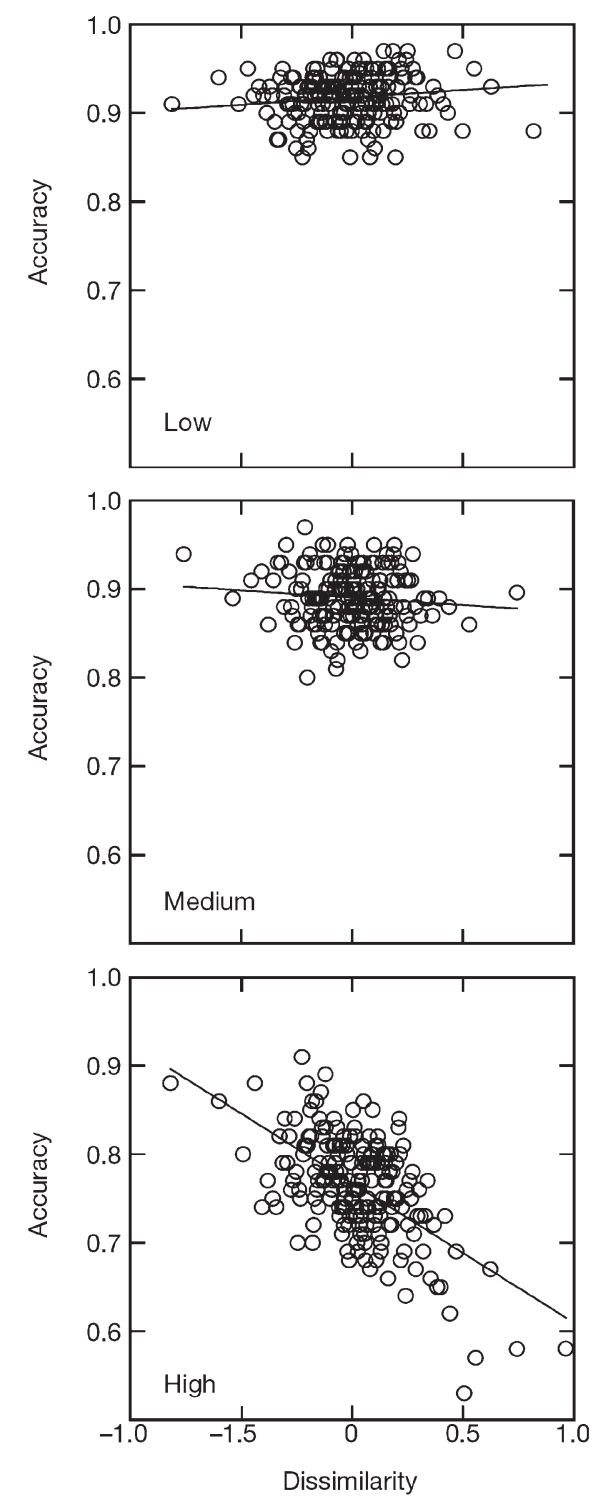

Figure 2. Detection accuracy of blocks of 100 trials as a function of crypticity of the target moth and dissimilarity between the target and the last previous correctly detected moth. Dissimilarity has been adjusted to remove the influence of mean phenotypic variance and mean population crypticity. Individual moth crypticity, $c$, increases from the top to the bottom panel: low ( $c$ $\leq 0.45)$, medium $(0.45<c \leq 0.6)$, and high $(c>0.6)$. Regression lines indicate the relationship between accuracy and dissimilarity within crypticity levels. 

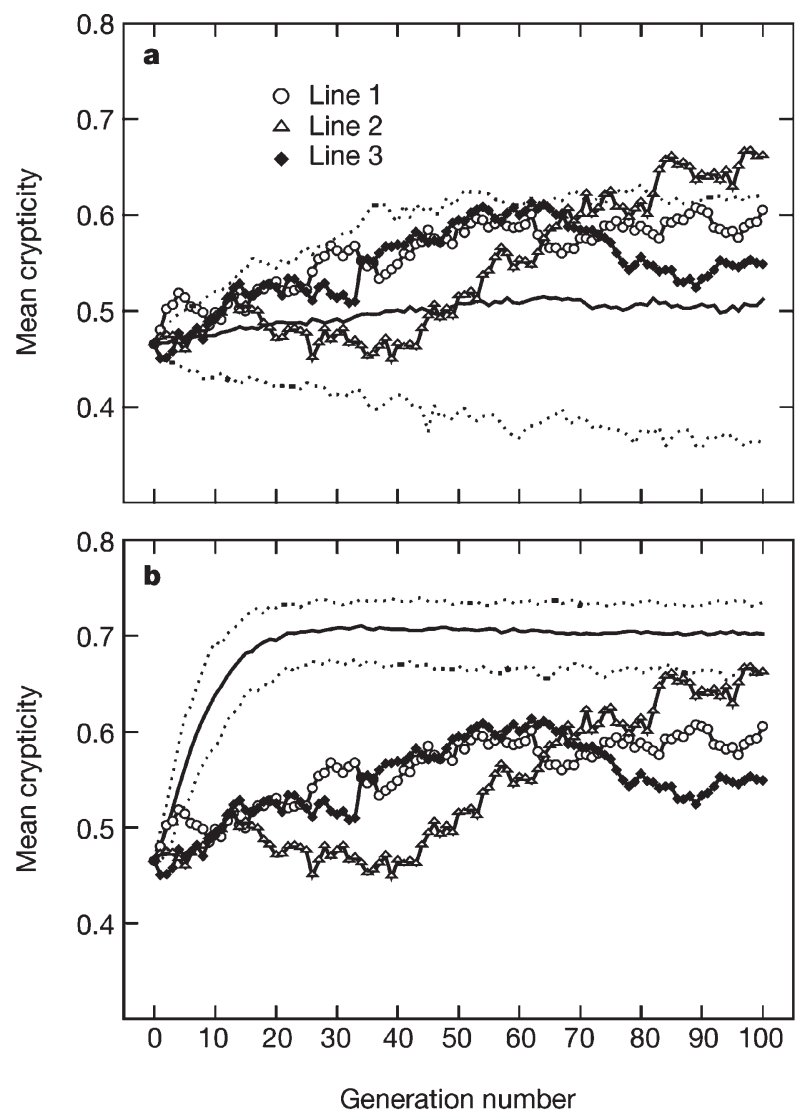

Figure 3. Changes in mean crypticity across successive generations in the three experimental lines (plotted with symbols), contrasted with the distribution of values from the two sets of control lines. Non-selected lines form the control group in $\mathbf{a}$; the control in $\mathbf{b}$ was produced by frequency-independent selection for crypticity based on parameters derived from global aspects of the jays' behavior. Graphs display medians (solid lines) and $95 \%$ confidence limits (dotted lines) from 200 replicate control lines. Crypticity increased across generations to some degree in all three treatments; the increase was greatest for the frequency-independent controls and least for the non-selected lines.

individuals from the hundredth generation (Figure 1b, c). Selection in favor of individuals that resemble the background has been invoked as the probable cause of cryptic coloration in prey species for over a century, 13,34 and there have been numerous demonstrations that predators preferentially feed on more conspicuous prey items., ${ }^{35-37}$ Our study is, however, the only work other than Endler's research on color-pattern selection in guppies $^{38}$ that has shown significant directional selection by predators over multiple successive prey generations when compared with a non-selected control.

Mean crypticity increased more gradually in the experimental lines than in the frequency-independent controls and was still significantly lower in the $\mathrm{F}_{100}$ generation (Figures $1 \mathrm{~b}$, $\mathrm{d}$ and $3 \mathrm{~b} ; F_{1,40596}$ $\geq 28.7, P<0.0001$ ). This should not be surprising, as frequency-dependent selection should enable infrequent, moderately cryptic phenotypes to persist long after a directional, frequency-independent process would have led to their extinction. In addition, if the jays were focusing their search on specific, salient features of individual moth phenotypes, they may often have overlooked even relatively conspicuous individuals, accentuating the disparity between experimental and control treatments.

\section{Selection effects on phenotypic variance}

In our final analysis, the role of frequency-dependent selection in promoting phenotypic variance was tested by comparing the diversity of phenotypes in the experimental lines with that in the control lineages. Phenotypic diversity increased in
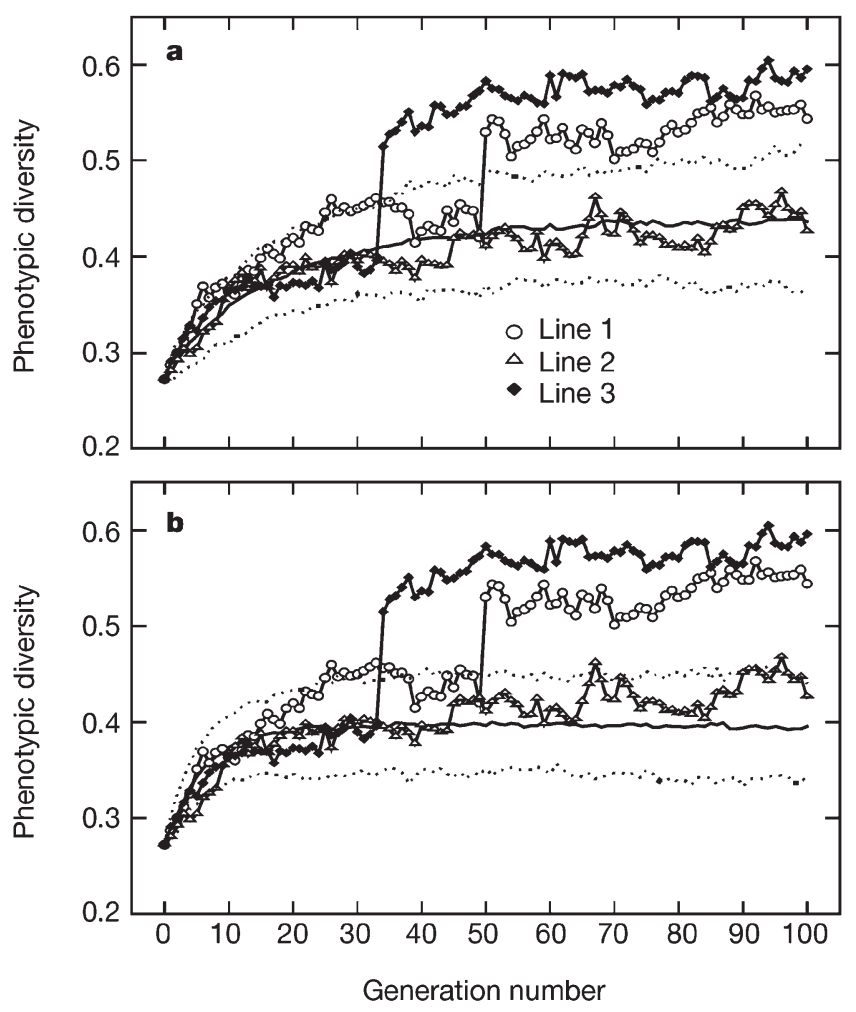

Figure 4. Changes in phenotypic variance of the digital moth population in the three experimental lines (plotted with symbols), contrasted with the distribution of values from the two sets of control lines. Non-selected lines form the control group in $\mathbf{a}$; the control in $\mathbf{b}$ was produced by frequency-independent selection for crypticity based on parameters derived from global aspects of the jays' behavior. Graphs display medians (solid lines) and $95 \%$ confidence limits (dotted lines) from 200 replicate control lines. Phenotypic variance increased to some degree in all three treatments, but the increase was greater in the experimental lines than in the controls. Experimental lines $I$ and 3 each exhibited an abrupt shift to a higher level of phenotypic variance at some point in the course of selection trials. In each case, the shift appeared to have been produced by the explosive spread of mutant regulatory genes affecting global levels of brightness or contrast.

the three experimental lines from 0.27 in the parental population to an average of 0.53 in the last five generations, an increase of $95 \%$ (Figure 4). Although the diversity of phenotypes also increased in both control treatments, all three experimental lines showed significantly higher diversity in the $\mathrm{F}_{100}$ generation than did the frequency-independent controls (Figures $1 \mathrm{~b}, \mathrm{~d}$ and $4 \mathrm{~b}$; $\left.F_{1,40596} \geq 21.44, P<0.0001\right)$, and two of the three lines were even higher than the non-selected controls (lines 1 and 3, Figures $1 \mathrm{~b}, \mathrm{c}$ and $\left.4 \mathrm{a} ; F_{140596} \geq 57.67, P<0.0001\right)$. The significantly higher variance exhibited in the experimental lines thus provides the first direct evidence of the polymorphic effects of frequency-dependent selection.

The observed increase in phenotypic diversity does not meet Ford's restrictive definition of polymorphism, ${ }^{39}$ in that the morphs were neither discontinuously variable nor controlled by a single switch gene. It would be surprising, however, if we had obtained discontinuous phenotypic variation in the absence of significant background heterogeneity ${ }^{35}$. Instances of similarly phenotypically diverse, or "massively polymorphic", cryptic species are by no means uncommon in the literature, having been recorded in brittle-stars, ${ }^{40}$ bivalves, ${ }^{4}$ grasshoppers, ${ }^{41}$ fish, ${ }^{35}$, 38 and noctuid moths. ${ }^{8-10}$ One feature that these disparate organisms have in common is high levels of local abundance, which ensures that predators will experience short time delays between successive encounters with the species. Short interprey intervals may tend to accentuate the influence of searching images, relative to other selective factors that affect prey color patterns. ${ }^{42}$ 
High phenotypic diversity can therefore be selected for in abundant prey species living in fine-grained habitats. In the next stage of our explorations of virtual ecology, we will introduce a range of heterogeneous backgrounds to examine the evolution of more classical, discontinuous polymorphisms. This will allow a direct test of the hypothesis that high phenotypic diversity is, as has been suggested, ${ }^{43}$ a step along the evolutionary path toward more discrete and genetically integrated polymorphisms.

\section{Methods}

\section{Subjects}

Four blue jays were captured in the field as nestlings and handreared in the laboratory. They were initially trained to peck at a single, invariant moth on a uniform grey background. Subsequently, negative trials without moths were added to the daily sessions, and the jays were given extensive discrimination training on a set of six fixed moth phenotypes. When the birds reached a criterion of $70-80 \%$ correct responses, we began to embed the moths in backgrounds of gradually increasing levels of difficulty. Once all four subjects could find the fixed set of moths at criterion levels on the experimental backgrounds, we introduced the birds to the parental population under non-evolving conditions. Stable performance by all subjects of at least $70 \%$ correct was required to begin selection trials.

\section{Genetic algorithms}

Moth phenotypes were developed from specifications in a virtual haploid chromosome, a string of 117 bytes. The wing pattern was encoded by 18 loci, each consisting of five bytes that defined an elliptical wing patch by specifying its location, its orientation, the ratio of its axis lengths, the spread of intensity from its centre, and its base intensity. The value of each pixel in the phenotype was determined by the additive result of multiple overlapping patches, which provided some redundancy and assisted in maintaining the level of genetic variance in the population in spite of repeated generations of selection.

The chromosome was divided into nine linkage groups, each consisting of two patch loci and a regulatory locus. Each regulatory locus included one gene for brightness, one for contrast, and one for the probability of crossing over. Once the primary pattern was decoded from the patch loci, the developmental algorithm calculated the mean values of the brightness and contrast genes and modified the final image accordingly. This feature enabled fine adjustments in the color pattern and added to the redundancy of genetic encoding.

Reproduction entailed choosing two different chromosomes from the population and recombining them into a single offspring genome. Moths that had been overlooked during predation trials were 2.5 times as likely to be chosen as the average detected individual. Within the detected group, moths were ranked in inverse order of the time the predator took to find them, and the highest-ranked individual had a $25 \%$ higher probability of being chosen than the lowest-ranked. ${ }^{44}$ To enable maintenance of integrated pattern features, recombination took place only between linkage groups, and the cross-over probability was determined by the combined values of the recombination regulators above and below the exchange point. Each offspring genome was subsequently subjected to a mutation process that randomly inverted individual bits with a probability of 0.003 (Reference no. 44). To standardize the impact of individual mutations, gene values were interpreted using Gray code, which minimizes the bit string distance between adjacent integer values. ${ }^{44}$

\section{Analytical measures}

The primary dependent variables in this study were the crypticity and the phenotypic variability of the moths. To quantify crypticity, we calculated the frequency distribution of pixel intensities for each moth and computed the average unsigned difference between the moth and background distributions. ${ }^{45}$ In contrast to other studies of the mechanism of crypticity, ${ }^{35}$ we found no indication that differences between the moths and the background in the spatial frequency or distribution of patch sizes significantly affected detectability.

The crypticity index was subsequently validated by testing the consequences of direct manipulation of background resemblance, as well as by demonstrating that moths with a higher crypticity index were more difficult for the jays to find. Detection accuracy in blocks of 50 experimental trials declined significantly as a function of moth crypticity $\left(r^{2}=0.33 ; t(1)=26.1 ; P<0.0001\right)$, and the response time for correct detections increased $\left(r^{2}=0.33 ; t(1)=5.2 ; P<0.0001\right)$.
To quantify phenotypic variability, we applied a non-parametric partitioning algorithm ${ }^{46}$ to the moth phenotypes in each generation, choosing a prototypical individual whose average distance from all others in phenotypic space (measured in terms of "taxonomic distance" ${ }^{\prime 7}$ ) was minimal. This distance for each moth expressed the magnitude of its deviation from the prototype, and the average deviation for each population provided a relatively bias-free estimate of phenotypic variability.

\section{References}

I. Dearn, J. M. in Biology of Grasshoppers (ed. Chapman, R. F. \& Joern, A.) 5 I7549 (Wiley, New York, 1990).

2. Halkka, O. \& Halkka, L. Population genetics of the polymorphic meadow spittlebug, Philaenus spumarius (L.). Evol. Biol. 24, I49-I9I (1990).

3. Edmunds, M. in Insect Defenses (ed. Evans, D. L. \& Schmidt, J. O.) 3-2I (SUNY, Albany, New York, 1990).

4. Whiteley, D.A.A., Owen, D. F. \& Smith, D.A. S. Massive polymorphism and natural selection in Donacilla cornea (Poli, I79I) (Bivalvia: Mesodesmatidae). Biol.J. Linn. Soc. 62, 475-494 (1997).

5. Sargent, T. D. Legion of Night: The Underwing Moths (Univ. Massachusetts Press, Amherst, 1976).

6. Sargent, T.D. On the maintenance of stability in hindwing diversity among moths of the genus Catocala (Lepidoptera: Noctuidae). Evolution 32, 424434 (1978).

7. Barnes, W. \& McDunnough, J. H. Illustrations of the North American species of the genus Catocala. Mem. Am. Mus. Nat. Hist. 3, part I, I-47 (1918).

8. Owen, D. F. \& Whiteley, D. Reflexive selection: Moment's hypothesis resurrected. Oikos 47, I I7-I I 20 (1986).

9. Common, I. F. B.A study of the ecology of the adult bogong moth, Agrotis infusa (Boisd.) (Lepidoptera: Noctuidae), with special reference to its behaviour during migration and aestivation. Aust.J. Zool. 2, 223-263 (1954).

10. Pruess, K. P. Migration of the army cutworm, Chorizagrotis auxiliaris (Lepidoptera: Noctuidae). I. Evidence for a migration. Ann. Entomol. Soc. Am. 60, 910-920 (1967).

II. Clarke, B. C. in Taxonomy and Geography (ed. Nichols, D.) 47-70 (Systematics Association, Oxford, 1962).

I2. Allen, J. A. Frequency-dependent selection by predators. Phil. Trans. R. Soc. Lond. B 3 19, 485-503 (1988).

13. Poulton, E. B. The Colors of Animals (Appleton, New York, 1890).

14. Tinbergen, L. The natural control of insects in pine woods. I. Factors influencing the intensity of predation by songbirds. Arch. Néerlandaises Zool. 13, 265-343 (1960).

I5. Bond, A. B. \& Riley, D.A. Searching image in the pigeon:A test of three hypothetical mechanisms. Ethology 87, 203-224 (1991).

16. Reid, P. J. \& Shettleworth, S. J. Detection of cryptic prey: Search image or search rate? J. Exp. Psychol. Anim. Behav. Process 18, 273-286 (1992).

17. Langley, C. M. Search images: Selective attention to specific visual features of prey.J. Exp. Psychol.Anim. Behav. Process 22, 152-163 (1996).

18. Bond, A. B. \& Kamil, A. C. Searching image in blue jays: Facilitation and interference in sequential priming. Anim. Learn. Behav. 27, 46I-47I (1999).

19. Bond, A. B. \& Kamil, A. C. Apostatic selection by blue jays produces balanced polymorphism in virtual prey. Nature 395, 594-596 (1998).

20. Rand, A. S. Predator-prey interactions and the evolution of aspect diversity. Atlas Simp. Biota Amazônica 5, 73-83 (1967).

2I. Ricklefs, R. E. \& O'Rourke, K. Aspect diversity in moths: A temperatetropical comparison. Evolution 29, 3/3-324 (1975).

22. Allen, J. A. Reflexive selection is apostatic selection. Oikos 5 I, 25I-253 (1988).

23. Pietrewicz,A.T. \& Kamil,A. C.Visual detection of cryptic prey by blue jays (Cyanocitta cristata). Science 195, 580-582 (1977).

24. Pietrewicz, A.T. \& Kamil, A. C. Search image formation in the blue jay ( $C y$ anocitta cristata). Science 204, I332-1333 (1979).

25. Kono, H., Reid, P. J. \& Kamil, A. C. The effect of background cuing on prey detection. Anim. Behav. 56, 963-972 (1998).

26. Fleishman, L. J., McClintock, W. J., D'Erth, R. B., Brainard, D. M. \& Endler, J. A. Colour perception and the use of video playback experiments in animal behaviour. Anim. Behav. 56, I035-1040 (1998).

27. Robinson, R. Lepidopteran Genetics (Pergamon, Oxford, 1971).

28. Nijhout, H. F. The Development and Evolution of Butterfly Wing Patterns (Smithsonian Institution, Washington DC, 1991). 
29. Carroll, S. B. et al. Pattern formation and eyespot determination in butterfly wings. Science 265, 109-I I 4 (1994).

30. Brakefield, P. M. et al. Development, plasticity and evolution of butterfly eyespot patterns. Nature 384, 236-242 (1996).

3I. Guilford, T. \& Dawkins, M. S. Search images not proven: A reappraisal of recent evidence. Anim. Behav. 35, 1838-1845 (1987).

32. Endler, J. A. in Behavioural Ecology 3rd. (eds. Krebs, J. R. \& Davies, N. B.) 169-196 (Blackwell Scientific, Oxford, 1991).

33. Bond, A. B. Visual search and selection of natural stimuli in the pigeon: The attention threshold hypothesis. J. Exp. Psychol. Anim. Behav. Process 9 , 292-306 (1983).

34. Wallace, A. R. Darwinism: An Exposition of the Theory of Natural Selection with Some of its Applications (MacMillan, London, 1891).

35. Endler, J.A. A predator's view of animal color patterns. Evol. Biol. I I, 3।9364 (1978).

36. Cott, H. B. Adaptive Coloration in Animals (Methuen, London, 1957).

37. Robinson, M. H. Defenses against visually hunting predators. Evol. Biol. 3, 225-259 (1969)

38. Endler, J.A. Natural selection on color patterns in Poecilia reticulata. Evolution 34, 76-9I (1980).

39. Ford, E. B. in Insect Polymorphism: Symposia of the Royal Entomological Society of London (ed. Kennedy, J. S.) Vol. I, I I- 19 (Royal Entomological Society, London, 196I).
40. Moment, G. B. Reflexive selection: a possible answer to an old puzzle. Science 136, 262-263 (1962)

4I. Nabours, R. K., Larson, I. \& Hartwig, N. Inheritance of color patterns in the grouse locust Acrydium arenosum Burmeister (Tettigidae). Genetics I8, |59-I7| (1933).

42. Plaisted, K. C. \& Mackintosh, N. J.Visual search for cryptic stimuli in pigeons: implications for the search image and search rate hypotheses. Anim. Behav. 50, I219-1232 (1995).

43. Darlington, C. D. \& Mather, K. The Elements of Genetics (Macmillan, New York, 1950).

44. Bäck, T. Evolutionary Algorithms in Theory and Practice (Oxford Univ. Press, New York, 1996).

45. Endler, J.A. Progressive background matching in moths, and a quantitative measure of crypsis. Biol.J. Linn. Soc. 22, 187-23I (1984).

46. Kaufman, L. \& Rousseeuw, P. J. Finding Groups in Data (Wiley, New York, 1990).

47. Sneath, P. H.A. \& Sokal, R. R. Numerical Taxonomy (Freeman, San Francisco, 1973).

\section{Acknowledgments}

The authors thank J.Allen, R. Balda, J. Endler,T. Getty, L. Harshman, S. Louda, D. Pilson, and S. Shettleworth for their comments and suggestions. This research was supported by a grant from the National Science Foundation. 